\title{
Right ventricular hypertrophy in a group of coalworkers
}

\author{
JUNE M FERNIE, AN DOUGLAS, D LAMB, V ANNE RUCKLEY \\ From the Institute of Occupational Medicine, Edinburgh, and the Department of Pathology, University of \\ Edinburgh
}

ABSTRACT The prevalence of right ventricular hypertrophy was studied in necropsy material from 215 coalworkers, a group which consisted of 115 men with simple or no pneumoconiosis and 100 with progressive massive fibrosis. Right ventricular hypertrophy was considered to be present if the ratio of the weight of the left ventricle plus septum to that of the right ventricle was less than $2: 1$. The prevalence of right ventricular hypertrophy was low $(15 \%)$ in the absence of progressive massive fibrosis and appeared to be related to emphysema or airways disease or both, and not to simple pneumoconiosis. It was evident only in subjects who had smoked. In subjects with progressive massive fibrosis the prevalence of right ventricular hypertrophy was higher (34\%) and it was occasionally seen in non-smokers. The prevalence increased with increasing size of lesion, and for any given size of lesion subjects with right ventricular hypertrophy had more panacinar emphysema than those without right ventricular hypertrophy. There was no relationship, however, between the extent of massive lesions or amount and type of emphysema and the degree of right ventricular hypertrophy.

Chronic airflow obstruction due to intrinsic airways disease and emphysema is the most frequent cause of cor pulmonale, a term conventionally applied to right ventricular hypertrophy secondary to structural or functional abnormality of the lung. ${ }^{1}$

In a study of coalworkers Gough found that complicated pneumoconiosis alone could be associated with cor pulmonale and suggested that this was due to the destruction of large areas of the pulmonary vascular bed resulting in pulmonary hypertension. ${ }^{2}$ Simple pneumoconiosis, however, rarely gives rise to pulmonary hypertension in the absence of concomitant obstructive lung disease or tuberculous scarring, ${ }^{23}$ although exceptions have been noted. ${ }^{4}$ As emphysema and airways disease are found in conjunction with complicated pneumoconiosis it is difficult to determine whether the cor pulmonale is due to the industrial lung disease or to the airways disease and emphysema, which may not be associated with the dusty occupation.

The aim of the present study was to verify observations of the prevalence of right ventricular hypertrophy in coalworkers with simple or no

Address for reprint requests: June M Fernie, Institute of Occupational Medicine, 8 Roxburgh Place, Edinburgh EH8 9SU.

Accepted 8 February 1983 pneumoconiosis. In addition, in these coalworkers and in coalworkers with complicated pneumoconiosis the associations between right ventricular hypertrophy and the size of the massive lesion (where present), type and extent of emphysema, indicators of airways disease, and smoking habit were investigated.

\section{Methods}

THE SUBJECTS

The study was carried out on the hearts and lungs of 345 coalworkers who during life had taken part in the pneumoconiosis field research ${ }^{5}$ of the National Coal Board. That research was based on 25 collieries selected as typical of the variety of underground conditions in British coalmines and comprised surveys of all coalworkers in these collieries at intervals of four to six years. Each survey included chest radiography, pulmonary function testing, administration of a respiratory symptoms questionnaire, and the taking of an occupational history.

The 345 coalworkers form a subgroup of the 500 subjects examined in a necropsy study of coalminers' lungs. ${ }^{67}$ Hearts were not available or were unsuitable for dissection for the remaining 155 subjects. 
The main source of the material was the pneumoconiosis medical panels and thus subjects were somewhat biased towards those with established disease. Nevertheless, some subjects with no radiographic evidence of coalworkers' pneumoconiosis were obtained.

\section{HEART EXAMINATION}

Hearts were dissected according to the method of Lamb $^{8}$ based on the technique of Fulton et al. ${ }^{9}$ After dissection the right ventricle (RV) and the left ventricle plus septum $(L V+S)$ were weighed separately. The ratio of the weight of the $L V+S$ to that of the RV is considered to provide the most appropriate method of assessing ventricular hypertrophy ${ }^{18}$ and in the present study a ratio of $(\mathrm{LV}+$ $\mathrm{S}): \mathrm{RV}$ of less than 2:1 was taken as indicating indisputable right ventricular hypertrophy.

A subject was excluded from the study if on dissection of the heart any valvular abnormality or previous myocardial damage (as shown by focal scarring measuring more than $1 \mathrm{~cm}$ in any plane) was apparent $(n=66)$ or if the isolated $L V+S$ weighed $225 \mathrm{~g}$ or more $(\mathrm{n}=51)$. A further 13 subjects were excluded for both reasons. Some subjects known to have had systemic hypertension were included in the absence of left ventricular hypertrophy since information about blood pressure was available for only a proportion of subjects and at varying times before death. Application of these selection factors resulted in a total loss of 130 subjects, leaving 215 available for analysis.

\section{LUNG EXAMINATION}

Lungs were inflated at necropsy; the pressures and duration of inflation were not known.

Transverse blocks from the lower-lobe bronchi, shown to be representative of the major bronchi, ${ }^{7}$ were taken, embedded in paraffin, and sectioned at $8 \mu \mathrm{m}$. Weigart's elastic stain and a Van Gieson counterstain were used. The mean bronchial glandto-wall thickness ratio ${ }^{10}$ was used to estimate the degree of mucous gland enlargement.

In general, the lungs had been cut in some way at necropsy. Slicing was completed, usually in the sagittal plane, at $1-\mathrm{cm}$ intervals and a representative slice was chosen for assessment from each of the pair of lungs. Initially subjects were divided into three pathological groups as follows: $\mathbf{M}$-subjects in whom all dust lesions were macules; $F$-subjects in whom one or more fibrotic lesions with a minimum diameter of $1 \mathrm{~mm}$ was present; and PMF (progressive massive fibrosis)-subjects in whom one or more fibrotic lesions with a minimum diameter of 1 cm was present.

Pathological groups $\mathrm{M}$ and $\mathrm{F}$ bear some relation to the radiological categories of simple pneumoconiosis in that, on average, $83 \%$ of $\mathrm{M}$ subjects will be in category $0 / 0$. In contrast, $70 \%$ of $F$ subjects will show opacities typical of simple pneumoconiosis. ${ }^{6}$

Emphysema was defined as the presence of air spaces of $1 \mathrm{~mm}$ or more in size and three main types were recognised. Centriacinar emphysema refers to any circumscribed emphysema separated from other lesions and from the interlobular septa by normal alveolar tissue, however small in area this may be. Panacinar emphysema refers to emphysema affecting all air spaces within an anatomical lung lobule, and paraseptal emphysema is emphysema occurring against the interlobular septa, subpleurally or in relation to the larger bronchi and blood vessels.

For assessment of emphysema and lesions of progressive massive fibrosis lung slices were divided into six zones as described by Heard. ${ }^{11}$ In non-PMF lungs the amount of emphysema in each of the six zones was estimated on a scale of $0-5$ (according to the number of fifths of the zone affected); this gave a total emphysema count expressed as thirtieths of the lung slice. Within each zone a visual assessment was then made of the relative contribution of the three types of emphysema (centriacinar, panacinar, and paraseptal) to the emphysema estimate for that zone. This enabled a division to be made of the total emphysema count into counts for each type. Although recorded, counts of paraseptal emphysema were not included in any analyses as the amounts present were usually negligible.

In PMF lungs the extent of the massive lesion or lesions in each zone was estimated on a scale of $0-5$, the total PMF area count being expressed as thirtieths of the lung slice.

The method of estimating emphysema was modified slightly for PMF lungs to take into account areas of lung tissue destroyed by massive fibrosis. Thus the amount of emphysema was expressed not as a count out of 30 but as a count out of 30 minus the total PMF area count; for example, given a total PMF area count of $8 / 30$ the amount of emphysema would be expressed as a count out of 22 . Counts of emphysema were then recalculated and expressed as the equivalent number of thirtieths of lung affected to allow comparison with non-PMF lungs.

Where both lungs had PMF area or emphysema estimates, or both, the average was used; otherwise estimates from a single lung were taken to represent the pair since in our experience estimates of emphysema or area of PMF lesions did not differ appreciably between left and right lungs. Subjects with unilateral PMF are an exception to this, but $\mathbf{3 0}$ of the 33 subjects with unilateral PMF included in the study had complete data for both lungs. One 
subject had no PMF area or emphysema data and in the two remaining subjects, both with a small unilateral lesion, the emphysema estimate used was that of the lung with the PMF lesion.

\section{RADIOGRAPHS}

Chest radiographs taken within four years of death were available for 128 of the 215 subjects. These radiographs were obtained from the pneumoconiosis medical panels, hospitals, or the pneumoconiosis field research surveys and were read according to the 1971 ILO U/C classification. ${ }^{12}$ For each subject the reading used was the average of the readings given by four National Coal Board doctors. $^{6}$

\section{PULMONARY FUNCTION DATA}

Of the 215 subjects studied, 70 had had measurements of forced expiratory volume in one second $\left(F_{1}\right)$ and forced vital capacity (FVC) taken within five years of death. These 70 subjects were representative of the 215 in terms of mean emphysema counts and bronchial gland-to-wall thickness ratios. The data were obtained from the pneumoconiosis medical panels or the pneumoconiosis field research surveys. As proportionately fewer of the subjects (non-PMF and PMF) with right ventricular hypertrophy had $\mathrm{FEV}_{1}$ measurements taken within five years of death we decided to supplement the data in these groups by including, for comment only, measurements taken more than five years before death.

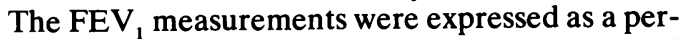
centage of the predicted values for age and height ${ }^{13}$ (FEV\%) and these values were used as indicators of the degree of airflow obstruction present.

Although $\mathrm{FEV}_{1}$ may be reduced in restrictive as well as obstructive lung disease it was apparent from an examination of the FVC\% (FVC percentage of predicted value) and $\mathrm{FEV}_{1}: \mathrm{FVC}$ ratios of the 70 subjects that obstructive lung disease was the predominant type.

\section{SMOKING HISTORIES}

Most of the smoking histories were obtained from the pneumoconiosis field research questionnaire

Table 1 Prevalence of right ventricular hypertrophy $(R V H)$ in three pathological groups

\begin{tabular}{|c|c|c|c|c|}
\hline & \multicolumn{3}{|c|}{ Pathological groups* } & \multirow[t]{2}{*}{ Total } \\
\hline & $M$ & $F$ & $P M F$ & \\
\hline $\begin{array}{l}\text { No of subjects with RVH } \\
\text { Total No of subjects } \\
\text { Prevalence of RVH (\%) }\end{array}$ & $\begin{array}{l}6 \\
39 \\
15 \cdot 4\end{array}$ & $\begin{array}{l}11 \\
76 \\
14 \cdot 5\end{array}$ & $\begin{array}{r}34 \\
100 \\
34\end{array}$ & $\begin{array}{r}51 \\
215 \\
23 \cdot 7\end{array}$ \\
\hline
\end{tabular}

data supplemented by panel records. There was good agreement between the two sources. Smoking histories were obtained for 204 of the 215 subjects, who were divided into three groups: smokers, exsmokers, and life-long non-smokers.

\section{Results}

RIGHT VENTRICULAR HYPERTROPHY IN NON-PMF SUBJECTS

Association with pneumoconiosis

A total of 17 of the 115 non-PMF $(M+F)$ subjects showed right ventricular hypertrophy and the proportions of $M$ and $F$ subjects with right ventricular hypertrophy were similar (table 1).

Chest radiographs taken within four years of death were available for 63 of the 115 subjects. Right ventricular hypertrophy was present in $18 \%$ of the 28 subjects in category $0 / 0$ and $17 \%$ of the 35 in category $0 / 1$ or above.

Association with emphysema, airways disease, and smoking habit

Emphysema was present in all 17 of the non-PMF subjects with right ventricular hypertrophy, and as a group those with right ventricular hypertrophy had significantly more emphysema $(p<0 \cdot 001$, Student's $t$ test) than those without.

Among the subjects for whom data on centriacinar and panacinar emphysema were available, counts of both types were significantly increased ( $p$ $<0.001$, Student's $t$ test) in subjects with right ventricular hypertrophy (table 2).

The pathological counterpart of the mucus hypersecretion typical of chronic bronchitis is enlargement of the bronchial mucous glands. In the non-PMF subjects there was no difference in the mean bronchial gland-to-wall thickness ratio between subjects with and without right ventricular hypertrophy.

All four of the subjects with right ventricular hypertrophy for whom recent $F E V_{1}$ data were available had airways obstruction with an FEV\% (FEV

Table 2 Emphysema counts (means $\pm S D$ ) in 102 non-PMF* subjects, with and without right ventricular hypertrophy $(R V H)$, for whom data were available on the type of emphysema

\begin{tabular}{llll}
\hline$R V H$ & \multicolumn{3}{l}{ Emphysema counts $t$} \\
\cline { 2 - 4 } & Total & Centriacinar & Panacinar \\
\hline Present $(\mathrm{n}=14)$ & $8 \cdot 5 \pm 3 \cdot 9$ & $3 \cdot 6 \pm 1 \cdot 7$ & $4 \cdot 7 \pm 3 \cdot 6$ \\
Absent $(\mathrm{n}=\mathbf{8 8})$ & $2 \cdot 9 \pm 4 \cdot 1$ & $1 \cdot 5 \pm 2 \cdot 1$ & $1 \cdot 3 \pm 3 \cdot 0$ \\
\hline *Progressive massive fibrosis-see under & "Methods-Lung \\
examination." & & \\
PExpressed as thirtieths.
\end{tabular}


percentage of predicted value) of $30 \%$ or less. Less recent $F E V_{1}$ data were available for a further six subjects in this group. All but one of these had an FEV\% of $50 \%$ or less. These low values were not matched by the 30 non-PMF subjects without right ventricular hypertrophy, for whom the mean FEV\% was $71 \%$.

An examination of smoking habit in the non-PMF group showed that right ventricutar hypertrophy was absent in all eight non-smokers and rarely present in the ex-smokers (table 3 ).

\section{RIGHT VENTRICULAR HYPERTROPHY IN PMF} SUBJECTS

The prevalence of right ventricular hypertrophy in subjects with PMF was $34 \%$, significantly higher ( $p$ $<0.001, \chi^{2}$ test) than in non-PMF subjects (table 1).

Of the 100 PMF subjects studied, 85 had complete PMF area estimates, emphysema estimates, and bronchial gland-to-wall thickness ratios.

Association with extent of massive lesion

When the 85 subjects were subdivided according to the extent of PMF the prevalence of right ventricular hypertrophy was seen to be significantly associated ( $p<0.001, \chi^{2}$ test) with the size of lesion. In subjects with small PMF lesions $(<1 / 30)$ the prevalence of right ventricular hypertrophy was the same as in non-PMF subjects, whereas in subjects with lesions of greater than 10/30 the prevalence of right ventricular hypertrophy was $83 \%$ (fig 1 ).
Table 3 Distribution of subjects with and without progressive massive fibrosis (PMF) by smoking habit and presence or absence of right ventricular hypertrophy $(R V H)$

\begin{tabular}{llllll}
\hline Smoking habit & Non-PMF & & & \multicolumn{2}{l}{ PMF } \\
\cline { 2 - 3 } \cline { 5 - 6 } & $\begin{array}{l}\text { RVH } \\
\text { present }\end{array}$ & $\begin{array}{l}\text { RVH } \\
\text { absent }\end{array}$ & & $\begin{array}{l}\text { RVH } \\
\text { present }\end{array}$ & $\begin{array}{l}\text { RVH } \\
\text { absent }\end{array}$ \\
\hline Non-smoker & - & 8 & 2 & 5 \\
Ex-smoker & 1 & 7 & 5 & 6 \\
Smoker & 14 & 77 & 26 & 53 \\
Unknown & 2 & 6 & 1 & 2 \\
\hline
\end{tabular}

Association with emphysema, airways disease, and smoking habit

Of the 85 subjects with PMF, those with right ventricular hypertrophy had significantly more emphysema than those without: this trend was similar for each size grouping of PMF (table 4). The $>$ 5-10 and $>10 / 30$ PMF groups were combined because of the small number of subjects in the latter group. When centriacinar and panacinar emphysema counts were considered separately the increased amount of emphysema in PMF subjects with right ventricular hypertrophy was due entirely to an increased amount of panacinar emphysema. In the "all subjects" group, for example, the mean total emphysema count of 8.6 in those with right ventricular hypertrophy comprised 2.2 for centriacinar and 6.1 for panacinar emphysema. In those subjects without right ventricular hypertrophy the mean total emphysema count of 4.4 comprised 1.6 for centriacinar and 2.5 for panacinar emphysema. The mean

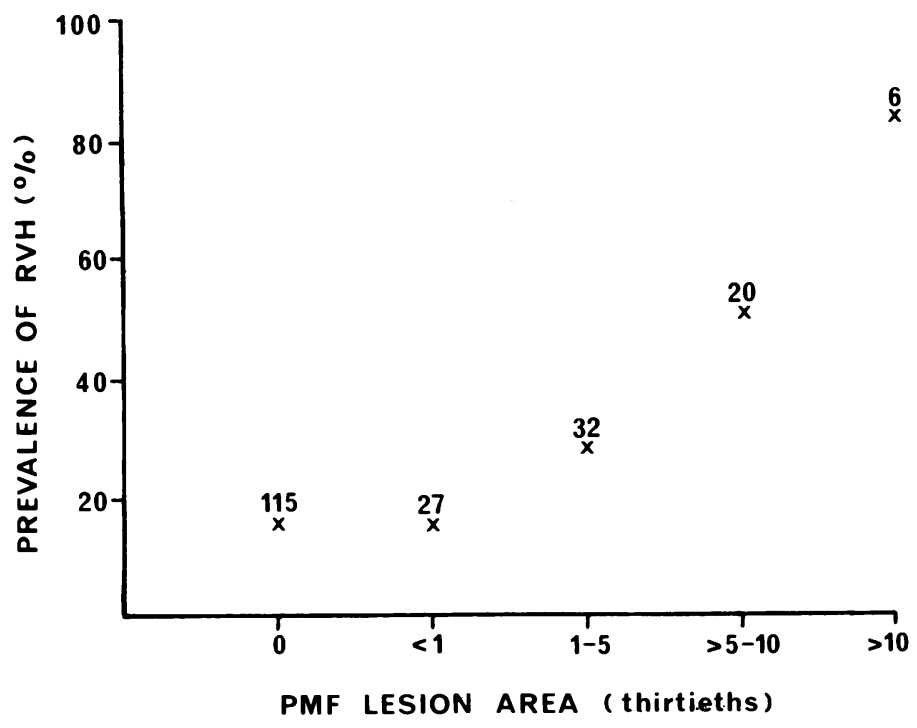

Fig 1 Prevalence of right ventricular hypertrophy in non-PMF and PMF subjects subdivided by extent of PMF (total number of subjects shown for each group). 
Table 4 Total emphysema counts (means $\pm S D$ ) in 85 subjects with progressive massive fibrosis (PMF), with and without right ventricular hypertrophy $(R V H)$, subdivided by extent of PMF

\begin{tabular}{llll}
\hline $\begin{array}{l}\text { PMF } \\
\text { area count }\end{array}$ & \multicolumn{2}{l}{ Total emphysema count } & \multirow{2}{*}{$p^{\dagger}$} \\
\cline { 2 - 3 } & $R V H$ present & $R V H$ absent & \\
\hline$<1$ & $8 \cdot 1 \pm 9 \cdot 0(4) \pm$ & $3 \cdot 2 \pm 4 \cdot 5(23)$ & NS \\
$1-5$ & $8 \cdot 2 \pm 4 \cdot 6(9)$ & $4 \cdot 6 \pm 5 \cdot 1(23)$ & NS \\
$>5$ & $8 \cdot 9 \pm 7.9(15)$ & $6 \cdot 3 \pm 5 \cdot 4(11)$ & NS \\
All subjects & $8 \cdot 6 \pm 7.3(28)$ & $4.4 \pm 4 \cdot 9(57)$ & $<0.01$ \\
\hline
\end{tabular}

*Expressed as thirtieths.

†Probability value (Student's $t$ test).

$\ddagger$ No of subjects in parentheses.

NS-not significant.

centriacinar counts of the two groups were not significantly different but the mean panacinar count was significantly increased ( $p<0.01$, Student's $t$ test) in those with right ventricular hypertrophy.

As with the non-PMF subjects, there was no difference in the mean bronchial gland-to-wall thickness ratio of PMF subjects with and without right ventricular hypertrophy.

$\mathrm{FEV}_{1}$ data obtained within five years of death were available for 10 of the PMF subjects with right ventricular hypertrophy and 26 of those without. For these two groups the mean values of FEV expressed as percentages of predicted values were $54 \%$ and $69 \%$. Although the difference was not significant (Student's $t$ test), only $20 \%$ of those with right ventricular hypertrophy had FEV\% values in what might be considered the normal range (FEV\% $>80 \%$ ), compared with $46 \%$ of those without right ventricular hypertrophy. Less recent $\mathrm{FEV}_{1}$ data were available for a further 22 of the PMF subjects with right ventricular hypertrophy. These values showed the same distribution as the values obtained within five years of death. Thus the FEV\% values of PMF subjects with right ventricular hypertrophy differed considerably from those of the non-PMF subjects with right ventricular hypertrophy, although mean emphysema counts for the two groups were similar.

When smoking habit was examined it was found that right ventricular hypertrophy was present in two of the seven non-smokers and in five of the 11 ex-smokers in the PMF group (table 3).

\section{PMF SUBJECTS WITH RIGHT VENTRICULAR HYPERTROPHY}

Of the 34 PMF subjects with right ventricular hypertrophy, 28 had both PMF area data and complete emphysema data. In these subjects no relationship could be shown between the degree of right ventricular hypertrophy (that is, decreasing heart weight ratio) and the PMF lesion area (fig 2) or the extent and type of emphysema.

\section{Discussion}

The present study has shown no evidence that there is an association between simple pneumoconiosis and right ventricular hypertrophy, the prevalence of the latter being the same in coalworkers with simple pneumoconiosis (defined in pathological or radiological terms) as in those with no pneumoconiosis. In these groups (the non-PMF subjects) the prevalence of right ventricular hypertrophy was low $(15 \%)$ and, where present, it was associated with evidence of severe airflow obstruction during life. Similar findings have been reported in other studies. ${ }^{23}$

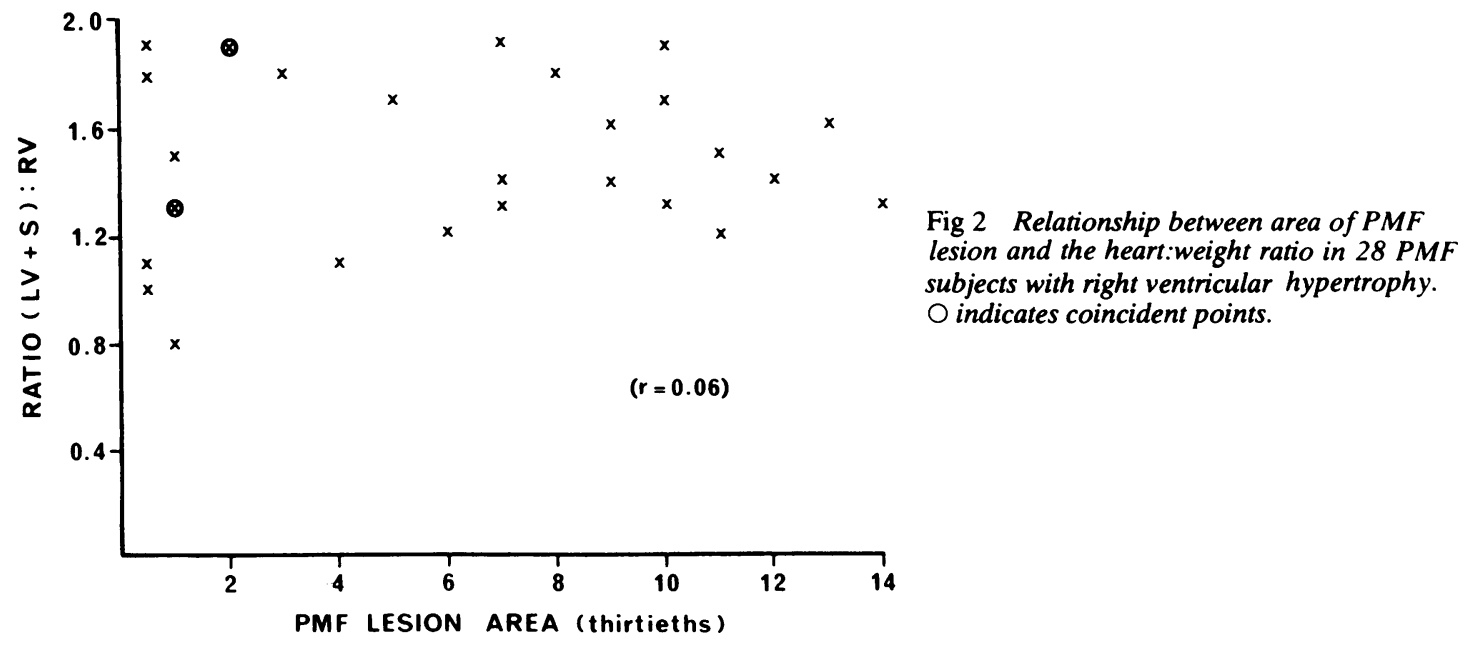


The possible causes of airflow obstruction and hence right ventricular hypertrophy are intrinsic airways disease and emphysema and in the nonPMF subjects there was evidence to suggest an association between emphysema and right ventricular hypertrophy. Relationships between emphysema and right ventricular hypertrophy have also been observed in miners and industrial workers with silicosis $^{14}$ and in coalworkers in contact with bituminous coal. ${ }^{15}$ Studies of right ventricular hypertrophy in the general population, ${ }^{16-24}$ however, have resulted in a divergence of opinion concerning such an association with disagreement, in particular, about whether the extent of emphysema and the size of the right ventricle are correlated and whether any association applies to a specific type of emphysema. These disagreements are largely the result of different methods of assessing right ventricular hypertrophy, one of which - the measurement of ventricular wall thickness-is considered to be unreliable. ${ }^{825}$ Another contributing factor has been the tendency of many workers to dismiss the fact that centriacinar and panacinar emphysema frequently coexist and to separate individuals according to the predominant type present. In the present study the types coexist but are considered separately and the results have shown that increased amounts of both centriacinar and panacinar emphysema are present in non-PMF subjects with right ventricular hypertrophy. The interpretation of these results is somewhat difficult, however, as counts of centriacinar and panacinar emphysema are significantly correlated with the total emphysema count $(r=0.74$ and 0.88 respectively) and also with each other $(r=0.35)$ in nonPMF subjects. For this reason it is impossible to determine which, if either, of the two types is specifically associated with right ventricular hypertrophy. Some workers ${ }^{20} 22$ have implicated centriacinar and others ${ }^{23}{ }^{24}$ panacinar emphysema.

The absence, however, of right ventricular hypertrophy in several subjects with gross emphysema, together with its presence in some with mild emphysema, precludes emphysema from being considered the sole cause of right ventricular hypertrophy in the non-PMF subjects and suggests that airways disease may also play a part. In fact, it has been reported that in people dying of chronic obstructive lung disease right ventricular hypertrophy is generally less noticeable or is altogether absent in those with extensive emphysema. ${ }^{26}$ The severity of the airflow obstruction seen in the non-PMF subjects with right ventricular hypertrophy, some of whom had minimal emphysema, is itself suggestive of severe airways disease.

In accord with other studies, ${ }^{24}{ }^{27}$ no relationship could be found between right ventricular hyper- trophy and large airways disease as measured by bronchial mucous gland size.

It was interesting, but not altogether surprising, to find that none of the non-smokers and few of the ex-smokers in the non-PMF group had right ventricular hypertrophy. Cigarette smoking is known to be associated with both emphysema and airflow obstruction, ${ }^{2829}$ and these were common features of those subjects with right ventricular hypertrophy.

When PMF is present the overall prevalence of right ventricular hypertrophy is much higher, the $34 \%$ found in the present study being similar to the $44 \%^{30}$ and $42 \%^{3}$ previously reported. In this study the prevalence of right ventricular hypertrophy increased with the extent of massive fibrosis, which is in accord with the report of an increased prevalence of right ventricular hypertrophy with increasing diameter of the largest PMF lesion. ${ }^{31}$ We have also shown that there is no direct quantitative relationship between extent of PMF and degree of right ventricular hypertrophy, which suggests that destruction of the vascular bed by massive fibrosis is not the sole cause of right ventricular hypertrophy in PMF subjects, but that other factors play a part. Again there was evidence for the role of emphysema, specifically panacinar emphysema, which may reflect the fact that panacinar emphysema comprises a greater percentage of the total emphysema count in PMF subjects $(64 \%)$ than in non-PMF subjects (48\%).

Right ventricular hypertrophy was present in five of the 11 ex-smokers in the PMF group and in two of the seven non-smokers, both of whom had large PMF lesions; thus a greater percentage of the exsmokers and non-smokers had right ventricular hypertrophy in the PMF group than in the non-PMF group. These differences were not, however, significant (exact test for $2 \times 2$ contingency tables), probably because of the small numbers of subjects.

When we considered the PMF subjects individually, it seemed likely that in some cases right ventricular hypertrophy had developed simply through destruction of the vascular bed by massive fibrosis, whereas in others it was probably attributable to emphysema or severe airways disease or both. These were the extreme cases, however, and probably most subjects developed right ventricular hypertrophy as a result of more than one process. It is noteworthy that some PMF subjects did not show right ventricular hypertrophy even when extensive PMF and severe emphysema were present. This lends further support to the idea that there are other factors, specifically associated with chronic obstructive lung disease, which may be more closely related to right ventricular hypertrophy. Relationships between right ventricular hypertrophy and 
disseminated bronchiolostenosis have already been reported, ${ }^{32}{ }^{33}$ and in four subjects dying from chronic obstructive lung disease who had no emphysema cor pulmonale was attributed to hypoxia. ${ }^{34}$ We realise that these factors may show a closer association with right ventricular hypertrophy than those we studied.

We would like to thank the staff of the pneumoconiosis medical panels for supplying the necropsy material and some of the chest radiographs, smoking histories, and pulmonary function data. We would also like to thank Miss Sandra Gauld for her statistical advice. The study was jointly funded by the National Coal Board and the Commission of the European Communities.

\section{References}

${ }^{1}$ World Health Organisation. Chronic cor pulmonale. Report of an expert committee (Geneva, 1960). Geneva: WHO, 1960. (Technical Report Series No 213.)

${ }^{2}$ Gough J. Pathological changes in the lungs associated with cor pulmonale. Bull NY Acad Med 1965;41:927-41.

${ }^{3}$ Wells AL. Cor pulmonale in coalworkers' pneumoconiosis. Br Heart J 1954;16:74-8.

${ }^{4}$ Lapp NL, Seaton A, Kaplan KC, Hunsaker MR, Morgan WKC. Pulmonary haemodynamics in coalworkers' pneumoconiosis. In: Walton WH, ed. Inhaled particles III. Old Woking, Surrey: Unwin Bros, 1971:645-56.

${ }^{5}$ Fay JWJ, Rae S. The Pneumoconiosis Field Research of the National Coal Board. Ann Occup Hyg 1959;1:149-61.

${ }^{6}$ Davis JMG, Chapman J, Collings P, et al. Autopsy studies of coalminers' lungs. Edinburgh: Institute of Occupational Medicine, 1979. (IOM Report TM/79/ 9.)

7 Ruckley VA, Chapman JS, Collings PL, et al. Autopsy studies of coalminers' lungs-phase II. Edinburgh: Institute of Occupational Medicine, 1981. (IOM Report TM/81/18.)

${ }^{8}$ Lamb D. Heart weights and assessment of ventricular hypertrophy. In: Dyke SC, ed. Recent advances in clinical pathology. Series 6. Edinburgh: Churchill Livingstone, 1973:138-48.

${ }^{9}$ Fulton RM, Hutchinson EC, Jones AM. Ventricular weight in cardiac hypertrophy. $\mathrm{Br}$ Heart $\mathrm{J}$ 1952;14:413-20.

${ }^{10}$ Reid L. Measurement of the bronchial mucous gland layer: a diagnostic yardstick in chronic bronchitis. Thorax 1960;15:132-41.

"Heard BE. Pathology of chronic bronchitis and emphysema. London: J and A Churchill, 1969:11.

${ }^{12}$ International Labour Office. ILO U/C international classification of radiographs of pneumoconioses, 1971. Geneva: ILO, 1972. (Occupational Safety and Health Series No 22.)

${ }^{13}$ Cotes JE. Lung function. 4th ed. Oxford: Blackwell Scientific Publications, 1979:369.

${ }^{14}$ Smidt U, Schnellbächer F. Right ventricular hypertrophy, verified by autopsy, and symptoms of its development in patients with silicosis and coalworkers' pneumoconiosis. Prax Klin Pneumol 1978;32:407-16.

${ }^{15}$ Naeye RL, Laqueur WA. Chronic cor pulmonale, its pathogenesis in Appalachian bituminous coalworkers. Arch Path 1970;90:487-93.

${ }^{16}$ Burrows B, Fletcher CM, Heard BE, Jones NL, Wootliff JS. The emphysematous and bronchial types of chronic airways obstruction. Lancet $1966 ; \mathrm{i}: 830-5$.

${ }^{17}$ Cromie JB. Correlation of anatomic pulmonary emphysema and right ventricular hypertrophy. Am is Rev Respir Dis 1961;84:657-62.

${ }^{18}$ Wyatt JP, Fischer VW, Sweet HC. The pathomorphology of the emphysema complex. Parts I and II. Am Rev Respir Dis 1964;89:533-60.

${ }^{19}$ Foraker AG, Bedrossian CWM, Anderson AE. Myocardial dimensions and proportions in pulmonary emphysema. Arch Path 1970;90:344-7.

${ }^{20}$ Hicken P, Heath D, Brewer D. The relation between the weight of the right ventricle and the percent of abnor- $\vec{t}$ mal air space in the lung in emphysema. J Pathol $\mathscr{\sigma}$ 1966;92:519-46.

${ }^{21}$ Hasleton PS. Right ventricular hypertrophy in emphysema. J Pathol 1973;110:27-36.

${ }^{22}$ Dunnill MS. An assessment of the anatomical factor in $\complement$ cor pulmonale and emphysema. J Clin Pathol $\overparen{\curvearrowright}$ $1961 ; 14: 246-58$.

${ }^{23}$ Sweet HC, Wyatt JP, Fritsch AJ, Kinsella PW. Panlobu- $\vec{\oplus}$ lar and centrilobular emphysema. Correlation of clinical findings with pathological patterns. Ann Intern Med 1961;55:565-81.

${ }^{24}$ Scott KWM. A pathological study of the lungs and heart in fatal and non-fatal chronic airways obstruction. Thorax 1976;31:70-9.

${ }^{25}$ Cullen JH, Kaemmerlen JT, Daoud A, Katz HL. A prospective clinical-pathologic study of the lungs and $\underset{\vec{F}}{\overrightarrow{2}}$ heart in chronic obstructive lung disease. Am Rev O Respir Dis 1970;102:190-204.

${ }^{26}$ Millard J. Pulmonary hypertension in chronic bronchitis. Thorax 1967;22:286 (abstract).

${ }^{27}$ Dunnill MS. Morphometry of the human lung in health and disease. In: Cumming G, Hunt LB, eds. Form and function in the human lung. Edinburgh: $\mathrm{E}$ and $\mathrm{S}$ Livingstone, 1968:24.

${ }^{28}$ Fletcher C, Peto R, Tinker C, Speizer FE. The natural history of chronic bronchitis and emphysema. London: Oxford University Press, 1976.

${ }^{29}$ Ryder RC, Dunnill MS, Anderson JA. A quantitative study of bronchial mucous gland volume, emphysema $\circ$ and smoking in a necropsy population. J Pathol 1971;104:59-71.

${ }^{30}$ Coggin CB; Griggs DE, Stilson WL. The heart in pneumoconiosis. Am Heart J 1938;16:411-21.

${ }^{31}$ James WRL, Thomas AJ. Cardiac hypertrophy in coal- -0 workers' pneumoconiosis. Br J Ind Med 1956;13:24- N 9.

${ }^{32}$ Bignon J, Khoury F, Even P, André J, Brouet G. Mor- $\omega$ phometric study in chronic obstructive bronchopulmonary disease. Am Rev Respir Dis 1969;99:669-95.

${ }^{33}$ Depierre A, Bignon J, Lebeau A, Brouet G. Quantita- $\frac{C}{\varnothing}$ tive study of parenchyma and small conductive airways $\stackrel{\oplus}{\rightarrow}$ in chronic non-specific lung disease. Chest 1972;62:699-708.

${ }^{34}$ Hentel W, Longfield AN, Vincent TN, Filley GF, Mitch- $\frac{\vec{P}}{\mathrm{D}}$ ell RS. Fatal chronic bronchitis. Am Rev Respir Dis 1963;87:216-27. 